\title{
Dementia with leucoaraiosis and dural arteriovenous malformation: clinical and PET case study
}

\author{
Patrizia Nencini, Domenico Inzitari, Jeremy Gibbs, Salvatore Mangiafico
}

\begin{abstract}
A case of rapidly progressive dementia with diffuse leucoaraiosis on CT was attributable to a supratentorial dural arteriovenous malformation. Positron emission tomography (PET) showed low cerebral blood flow and high oxygen extraction ratio throughout the cerebral hemispheres indicating a state of chronic haemodynamic compromise which could predispose to the development of a vascular dementia. CT images of dilated intracerebral veins suggested that a venous drainage overload rather than a vascular steal phenomenon might be involved in the pathophysiology of the dementia of vascular origin.
\end{abstract}

(F Neurol Neurosurg Psychiatry 1993;56:929-931)

Dural arteriovenous malformations (AVM) represent $10 \%$ to $15 \%$ of all intracranial AVM. ${ }^{1}$ The most common clinical presentations of dural AVM are vascular bruit, headache, and, less often, increased intracranial pressure or intracranial haemorrhage. ${ }^{23}$ Dementia in relation to dural AVM, as in our case, is rare. ${ }^{1-3}$

Department of

Neurological and

Psychiatric Sciences,

University of

Florence, Florence,

Italy

P Nencini

D Inzitari

Neuroradiology

Service, Careggi

Hospital, Florence,

Italy

$S$ Mangiafico

MRC Cyclotron Unit, Hammersmith

Hospital, London, UK

J Gibbs

Correspondence to:

Dr Patrizia Nencini,

Dipartimento di Scienze

Neurologiche e

Neurologiche e

Morgagni 85, 50134

Firenze, Italy.

Received 27 August 1992

and in revised form

20 November 1992

Accepted 27 November 1992 possible. Neurological examination showed no focal motor deficit. Tendon reflexes and plantar responses were normal bilaterally.
Index to nose and heel to knee tests were performed correctly. Sucking and bilateral grasp reflexes were present. The patient had urinary incontinence. General medical examination was normal. No bruit was heard in the supraclavicular fossa, neck, or head. Optic fundi was normal.

Routine blood tests, CSF, and ECG were all normal. EEG showed diffuse slowing of brain electrical activity and no high voltage periodic waves. A non-enhanced brain CT revealed mild ventricular enlargement without cortical atrophy, and bilateral marked hypodensity of the subcortical white matter, especially in frontal regions. The infusion of contrast medium was followed by vermiform periventricular and subcortical enhancement (fig). Selective cerebral angiography showed multiple hypertrophic branches of both external carotid arteries (that is, left middle meningeal, accessory meningeal, and superficial temporal arteries; and right superficial temporal and middle meningeal arteries). These branches fed a dural AVM at the vertex which drained into an enlarged superior sagittal sinus (fig).

The patient progressively worsened and 2 months after admission, he appeared severely demented, aphasic, and ataxic while walking. At this time, a positron emission tomographic (PET) study was carried out on an ECAT II (EG and G Ortec, Oak Ridge, TN, USA) scanner, with a transaxial resolution of $16 \times$ $16 \mathrm{~mm}$ full width half maximum (FWHM) at the MRC Cyclotron Unit, Hammersmith Hospital, London. Data were collected from three transaxial planes, parallel to the orbitomeatal line $(O M+4.6 \mathrm{~cm}$; OM $+6.6 \mathrm{~cm}$; $\mathrm{OM}+8.6 \mathrm{~cm})$. Cerebral blood flow $(\mathrm{CBF})$, cerebral metabolic rate of oxygen $\left(\mathrm{CMRO}_{2}\right)$, and oxygen extraction ratio (OER) were measured by the steady state technique with continuous inhalation of $\mathrm{C}^{15} \mathrm{O}_{2}$ and ${ }^{15} \mathrm{O}_{2} \cdot{ }^{4} \mathrm{In}$ view of the patient's vascular malformation, $\mathrm{CMRO}_{2}$ and OER data were corrected for cerebral blood volume by means of a ${ }^{11} \mathrm{CO}$ study. ${ }^{5}$ Flow and metabolic data were analysed by hemispheric means of cortical and white matter regions at different levels. CBF was low in both cerebral cortex and deep structures; only occipital cortex seemed to be spared. There was also a symmetrical reduction of $\mathrm{CMRO}_{2}$, but this reduction was 

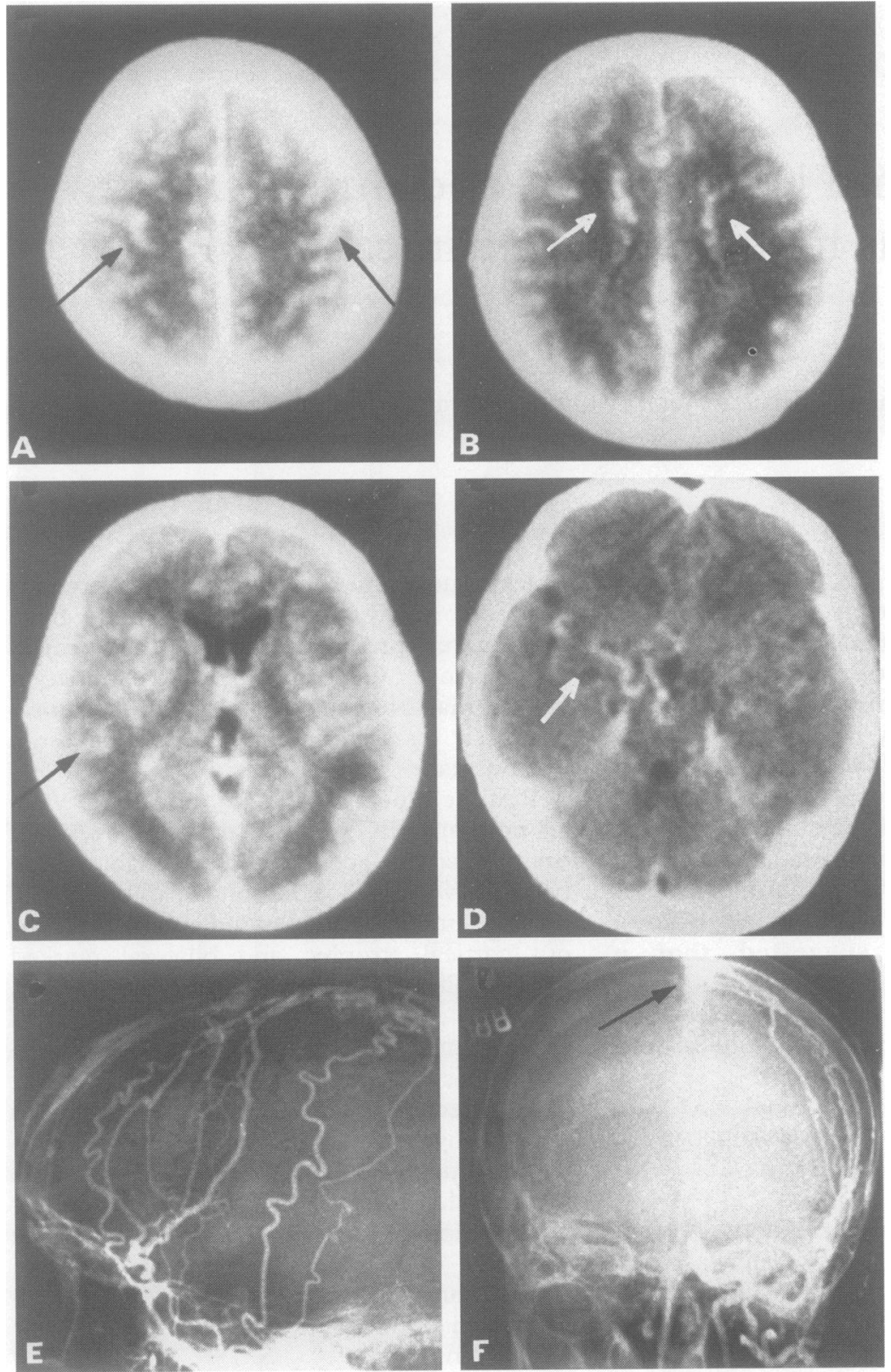

Figure Contrast enhanced CT scan: (A) congestion of cortical veins (arrows); (B) congestion of cortical veins and choroid plexuses (arrows), and marked hypodensity (leucoaraiosis) of subcortical white matter; (C) congestion of cortical veins (arrow); (D) congestion of basal veins (arrow). Left external carotid arteriogram: (E) lateral view, showing enlarged and tortuous middle meningeal, accessory meningeal, and superficial temporal arteries; (F) anteroposterior view, showing early filling of sagittal sinus (arrow).

less marked than that of CBF, and OER was consequently high. This pattern of very low perfusion, moderately reduced $\mathrm{CMRO}_{2}$ and high OER is indicative of impaired haemodynamic and oxygen carriage reserves ${ }^{6}$ and it was most severe in the top plane (table).

Table Haemodynamic and metabolic parameters (mean) in grey and white matter $(\mathrm{OM}+8.6 \mathrm{~cm}$ slice $)$

\begin{tabular}{|c|c|c|c|c|c|c|}
\hline & \multicolumn{3}{|c|}{ Grey matter } & \multicolumn{3}{|c|}{ White matter } \\
\hline & $C B F$ & $\mathrm{CMRO}_{2}$ & $O E R$ & $C B F$ & $\mathrm{CMRO}_{2}$ & $O E R$ \\
\hline $\begin{array}{l}\text { Case } \\
\text { Controls^ } \\
\text { range }\end{array}$ & $\begin{array}{l}15 \cdot 4 \\
59 \cdot 4 \\
41 \cdot 5-92 \cdot 5\end{array}$ & $\begin{array}{l}3 \cdot 0 \\
5 \cdot 3 \\
4 \cdot 2-7 \cdot 1\end{array}$ & $\begin{array}{l}0.9 \\
0.5 \\
0.4-0.6\end{array}$ & $\begin{array}{l}7 \cdot 7 \\
21 \cdot 2 \\
17 \cdot 5-24 \cdot 5\end{array}$ & $\begin{array}{l}1 \cdot 5 \\
1 \cdot 8 \\
1 \cdot 5-2 \cdot 1\end{array}$ & $\begin{array}{l}0.9 \\
0.5 \\
0.1-0.6\end{array}$ \\
\hline
\end{tabular}

ऋ 12 controls, age $30-74$ years. CBF $(\mathrm{ml} / 100 \mathrm{ml} / \mathrm{min})=$ cerebral blood flow; $\mathrm{CMRO}_{2}(\mathrm{ml}$ $\left.\mathrm{O}_{2} / 100 \mathrm{ml} / \mathrm{min}\right)=$ cerebral metabolism rate of oxygen; $\mathrm{OER}=$ oxygen extraction ratio.
Ten days after the PET study, the patient suddenly developed a right hemiparesis. A ligation of left external carotid and right superficial temporal arteries was performed but no clinical improvement was obtained. Four months after the admission, the patient died from bronchopneumonia. Necropsy was not performed.

\section{Discussion}

We suggest that the rapidly progressive dementia observed in our case was due to the dural AVM. Other causes of subacute dementia have been ruled out, in particular we excluded Creutzfeldt-Jacob disease on the basis of the clinical and EEG findings. Although rare, mental deterioration can occur with dural AVM. It has been reported mainly in dural AVM located in the posterior fossa and draining into the transverse sigmoid sinus. ${ }^{1-3}$ However, a case of progressive dementia associated with direct drainage of extracranial arteries into the superior sagittal sinus has been reported by Friede and Schubiger. ${ }^{7}$ Angiographic findings in this case were remarkably similar to those observed in our case. Pathological study showed arterialisation of the wall of the sinus and excessively distended veins in the leptomeninges and cerebral white matter with thickened fibrotic walls. Widespread patches of myelin loss around these abnormal vessels were also observed.

Areas of leucoaraiosis on CT scan have been reported in three patients with dural AVM and mental deterioration. ${ }^{3}$ In these patients, intravenous contrast infusion showed areas of vermiform or patchy enhancement. Diffuse CT hypodensity indicating subcortical white matter disease may be present in other dementing disorders, including cerebromeningoangiomatosis described by Divry and van Bogaert ${ }^{8}$, and Binswanger's subcortical encephalopathy. Chronic hypoperfusion is postulated among the possible causes of white matter lesions in Binswanger's encephalopathy ${ }^{9}$ and, in leucoaraiosis. ${ }^{10}$

In our case, the PET findings of low CBF and high OER are consistent with a state of diffuse, chronic vascular insufficiency. Little quantitative information on haemodynamic or metabolic effects of AVM is available and, to our knowledge, this is the first PET study of a dural AVM. Recently, Tyler and coworkers $^{11}$ studied 17 patients with intracerebral AVM by PET and observed widespread metabolic and haemodynamic abnormalities both in ipsilateral regions remote from the lesion and in the contralateral hemisphere. De Reuck et al $^{12}$ studied two cases of cerebral AVM, finding areas of decreased blood flow and oxygen metabolism at a distance from the malformation. Therefore, AVM can modify cerebral haemodynamics in adjacent or distant regions. The validity of the oxygen-15 steady state model in the presence of AVM has been demonstrated by Lammertsma et al. ${ }^{13}$ 
Concerning the pathogenesis of cerebral hypoperfusion in dural AVM, two main mechanisms can be hypothesised: (i) "steal" by the malformed vessels at the expense of the cerebral parenchyma and (ii) increase of the dural venous sinus pressure due to shunting from the arterial to the venous system. ${ }^{14}$ Diaschisis has never been described to occur in AVM. In our case, it is difficult to attribute the symptoms to a steal mechanism because all the enlarged feeding arteries rose from the external carotid arteries, and the angiograms showed no definite evidence of shunting from the internal to the external carotid circulation. Contrast CT scans displayed a vermiform enhancement owing to dilatation of the intraparenchymal venous system. These findings are compatible with an overload of venous drainage which may produce a chronic and critical reduction of cerebral perfusion pressure, particularly in the more vulnerable deep tissues.

Although not all the clinical criteria of vascular dementia (DSM-III-R) were fulfilled, the dementia presented by our case is consistent with the diagnosis of vascular dementia: there was evidence of vascular disease of the brain, the course was punctuated by strokelike episodes, and the features of dementia were those characteristic of subcortical dementia, proposed as typical of vascular dementia. ${ }^{15}$ Chronic ischaemia has been questioned as a cause of vascular dementia. ${ }^{16}$ However, modern imaging techniques frequently reveal abnormalities in the deep white matter which is particularly vulnerable to transient perfusion failure and infarction, indicating that multiple cortical infarcts cannot be considered the only cause of dementia of vascular origin. ${ }^{17}$ This report confirms that, at least in certain cases, chronic haemodynamic compromise caused by increased venous back pressure may cause vascular dementia.
We thank members of the Clinical Neuroscience, Chemistry and Methods Sections of the MRC Cyclotron Unit for making this study possible. We are also very grateful to Dr RSJ Frackowiack for his helpful comments during the preparation of this article.

1 Hunt WE. Dural arteriovenous malformations. In: Wilson $\mathrm{CB}$, Stein $\mathrm{BM}$, eds. Intracranial arteriovenous malformations. Current neurological practice. Baltimore-London: William \& Wilkins 1984; vol 1,222-33.

2 Obrador S, Soto M, Silvela J. Clinical syndromes of arteriovenous malformations of the transverse-sigmoid sinus. $\mathcal{F}$ Neurol Neurosurg Psychiatry 1975;38:436-51.

3 Miyasaka $\mathrm{K}$, Takei $\mathrm{H}$, Nomura $M$, et al. Computerized tomography findings in dural arteriovenous malformations. F Neurosurg 1980;53:698-702.

4 Frackowiak RS, Lenzi GL, Jones T, Heather JD. Quantitative measurement of regional cerebral blood flow and oxygen metabolism in man using ${ }^{15} \mathrm{O}$ and flow and oxygen metabolism in man using $O$ and positron emission tomography: theory, procedure, and
normal values. $\mathcal{F}$ Comput Assist Tomogr 1980;4:727-36.

5 Phelps ME, Huang SC, Hoffman EJ, Kuhl DE. Validation of tomographic measurement of cerebral blood volume with C-11- labeled carboxyhemoglobin. $\mathcal{f} \mathrm{Nucl}$ Med 1979;20:328-34.

6 Frackowiak RSJ. The pathophysiology of human cerebral ischaemia: a new perspective obtained with positron tomography. Quat f Med 1985;57:713-27.

7 Friede RL, Schubiger O. Direct drainage of extracranial arteries into the superior sagittal sinus associated with dementia. $\mathcal{F}$ Neurol 1981;225:1-8.

8 Bussone G, Parati EA, Boiardi A, et al. Divry-Van Bogaert syndrome. Clinical and ultrastructural findings. Arch Neurol 1984;41:560-2.

9 De Reuck J, Crevits L, De Coster W, Sieben G, van der Eecken H. Pathogenesis of Binswanger chronic progressive subcortical encephalopathy. Neurology 1980;30: 920-8.

10 Kobari M, Meyer JS, Ichijo M, Oravez WT. Leukoaraiosis: correlation of $M R$ and $C T$ findings with blood flow, atrophy, and cognition. AFNR 1990;11:273-81.

11 Tyler JL, Leblanc R, Meyer E, et al. Hemodynamic and metabolic effects of cerebral arteriovenous malformations studied by positron emission tomography. Stroke 1989;20:890-8.

12 De Reuck J, Van Aken J, Van Landegem W, Vakaet A. Positron emission tomography studies of changes in cerebral blood flow and oxygen metabolism in arteriovenous malformation of the brain. Eur Neurol 1989;29:294-7.

13 Lammertsma AA, Jones T. Correction for the presence of intravascular oxygen-15 in the steady-state technique for measuring regional oxygen extraction ratio in the brain. 1. Description of the method. 7 Cereb Blood Flow Metab 1983;3:416-24.

14 Lamas E, Lobato RD, Esparza J, Escudero L. Dural posterior fossa AVM producing raised sagittal sinus pressure. $\mathcal{f}$ Neurosurg 1977;46:804-10.

15 Cummings JL. Subcortical vascular dementia as a manifestation of cerebrovascular disease. NINDS/AIREN International Workshop on Vascular Dementia. Bethesda, MD, 19-21 April, 1991.

16 Brust JC. Vascular dementia - still overdiagnosed. Stroke 1983;14:298-300.

17 Scheinberg P. Dementia due to vascular disease-a multifactorial disorder. Stroke 1988;19:1291-9. 